\title{
FOREIGN AID ALLOCATION: A NEURAL NETWORK APPROACH
}

\author{
Sevinc Rende \\ Isik University • Istanbul, Turkey
}

\section{ABSTRACT}

During the last twenty years, there have been strong supporters of foreign aid, and equally strong critiques. The debate is based on an effort to establish a causal relationship between foreign aid and economic growth, and it is still ongoing. Rather than seeking to uncover the causal relationships, I examine foreign aid and its relation to structural indicators in aid dependent countries using a special type of artificial neural networks, known as Kohonen maps. The findings suggest that aid allocation and coordination could be based on institutional and climate-based similarities across recipient countries rather than the geographical proximity or the cultural ties, or preferences, between the donor and recipient countries.

JEL Codes: F35, O1, D63, C45

Key Words: ODA, aid, aid distribution, Kohonen maps, machine learning, data mining

\section{INTRODUCTION}

The role of foreign aid in economic development is important for at least two reasons. First, economic development in poor countries involves importing of some of the institutions, norms and sometimes industrial and technical goods of advanced economies. Second, foreign aid changes the relationship between the state, civil society and private sector in the delivery of public goods and services in the aid-recipient economies.

During the last twenty years, there have been strong supporters of foreign aid, and equally strong critiques (Gulrajani, 2011). The debate is based on an effort to establish and measure a causal relationship between foreign aid to economic growth, and it is still ongoing. The methodological challenge has been identifying the counterfactual, namely what kind of development trajectory the aid-recipient countries would have followed in the absence of foreign aid. The prevalent opinion in the literature seems to be that foreign aid is a tool that may not be efficient in promoting growth in poor countries, but has been shown to be effective in improving outcomes that carry intrinsic value for human life, such as health and education (Mishra and Newhouse, 2009; Doucouliagos and Paldam, 2011; d'Aiglepierre and 
Wagner, 2013).

The non-linear interactions involved in the delivery of foreign aid in a complex setting, however, make a full accounting of causal relationships extremely difficult. Even if we were able to measure causal relationship between foreign aid and economic growth, it would probably surprise no one that no two episodes of foreign aid flow have achieved their effect exactly same way in two different countries. What might be the reasons for this complexity? First, the delivery of aid involves interdependent policies within and between the aid institutions and the state. Some of these relationships are transnational, others are local. Second, receiving foreign aid shifts the production and distribution structure in the economy in the recipient states. As a result, a clear and directional attribution of development outcomes to aid is challenging.

In this study, I propose an alternative perspective. Rather than seeking to uncover the causal relationships between foreign aid and development outcomes, I document the potential benefits of allocating foreign aid by relying on structural similarities between the aid-recipient countries, rather than allocating aid by cultural ties or preferences between donor and aid recipient countries. The methodology does not neglect the importance of the causal relationship of aid effectiveness, namely "what works?", but focuses on "why does it work?", a pragmatic approach which may be more relevant for the poor living in aid-recipient countries. For this purpose, I examine allocation of foreign aid and its relation to institutional indicators using a special type of artificial neural networks, known in the literature as Kohonen selforganizing maps (Kohonen maps). The Kohonen map is a particularly useful tool for studying the complex factors that may play a role in foreign-aid allocation because focusing on the similarities across institutional structures of aid-recipient countries promotes both mutual cooperation and consultation in policy development in these countries.

I begin with a review of relevant literature and introduce the conceptual framework, followed by a description of Kohonen maps. I then identify a number of indicators that are highlighted in the literature on foreign aid and discuss the results, supported by selected examples. In conclusion, I evaluate the contribution of Kohonen maps to the discussions on the efficiency of foreign aid allocation. 


\section{LITERATURE REVIEW}

A quick exploration of the literature highlights that the sheer scale and complexity of foreign aid delivery presents a major puzzle in itself, even before attempting to measure its effectiveness. As a result, there is a wide and diverse body of literature examining the causal relationship between aid and economic growth, as well as a wealth of studies examining the factors influencing the effective delivery of aid.

Studies exploring the causal relationship from development aid to economic growth have found mixed results. Some studies find that foreign aid helps economic growth, others assert that foreign aid and economic growth have no statistically significant relationship, and a significant number of studies focus on the fragility of the results to changes in coverage in data and the definition of the variables undertaken (Burnside and Dollars, 2000; Hansen and Tarp, 2001; Easterly, 2003; Kourtellos et. al., 2007; Doucouliagos and Paldam, 2008; Kimura et. al.. 2012; Lof et. al., 2014). A good review on the aid literature is provided by Arndt et. al. (2010), who suggest that identifying theoretically and practically acceptable counterfactuals in searching for aid effectiveness on economic growth has proved to be elusive. Furthermore, the objectives for aid may vary between the donor and recipient countries (Gomanee et. al., 2005). Several other studies concentrate on the variations of aid types to seek for a causal relationship. Looking at the contribution of developmental and non-developmental aid to economic growth, Minoiu and Reddy (2010) find that only the type of "aid expended in a manner to promote development" contributes to economic growth.

In a recent study, Arndt et. al. (2014) meet these challenges with a combination of growth empirics and reduced form estimates of aggregate and intermediate outcomes. Their findings suggest that investments in human and physical capital seem to be the most effective transmission channels that lead from foreign aid to economic growth. De Matteis (2013) however, argues that aid is more effective when it focuses on poverty, rather than on growth. Even then, the 2008 global recession and its repercussions may reduce the size of aid budgets to a level of insignificance as a contribution to anti-poverty programs in the recipient countries (Kjeizer, 2012).

A considerable number of studies give particular attention to the variations in the aid allocation. Here, the focus has been on understanding the institutional context within which foreign aid operates. A framework for understanding the allocation of aid is offered by McGillivray (2004), who derives his classification from a close study of descriptive and prescriptive approaches to aid allocation on 
the one hand, and actual allocations, on the other. The main competing explanations for the variations in aid allocation are donor-related parameters and the institutional environment in aid recipient countries. Some authors have emphasized donor-related factors that may regulate the delivery of aid, such as the relationship between aid commitments and disbursements, multilayered donor objectives, the cultural values of and public and political support for aid in the donor country, and donor policy rules (Torsvik, 2005; Dalgaard, 2008; Ball, 2010; Hudson, 2013; Djankov et. al., 2013; Fuchs, et.al., 2015). Others have investigated the relevant indicators for aid allocation in the recipient countries, such as democracy, conflict, the effectiveness of rules and regulations, and absorption capacity of the government (Kosack, 2003; Busse and Gröning, 2009; Feeny and de Silva, 2012; Kersting and Kolby, 2014; Winters and Martinez, 2015).

Following the inclusion of development aid as the eighth goal of the Millennium Development Goals, a vast literature revealed the complex economic environment within which aid operates, both at the national and international levels. However, the connection between theory and practice in the field has not been able to meet the challenge of causal relationships to adequately test the usefulness of foreign aid. Ideally, to address poverty reduction and to support economic growth, one has to find ways to move from theory to applications to address the multilayered factors that influence aid effectiveness. As a result, an analysis of clustering of the recipient countries by aid-relevant indicators has the potential to highlight and develop pragmatic policy proposals.

\section{METHODOLOGY}

As a special case of artificial neural networks, Kohonen maps allow multidimensional data to be projected onto a two dimensional space to facilitate clear visualization and easy identification of clusters with similar characteristics. The methodology is developed by mimicking neural connections to provide pattern recognition by machine learning and to detect relationships in large datasets (Jagric et al 2015). The network is a non-linear vector projection of a multi-dimensional input space into lower output dimensions, while preserving the topology of the input space. In other words, the algorithm of Kohonen maps seeks to reduce a high dimension input data, $n x d$ onto a two-dimensional grid while preserving the most important topological relationships. In doing so, the algorithm reveals the associations which cannot be easily visualized at high dimensions. 


\section{Figure 1}

\section{A Typical SOM Representation}
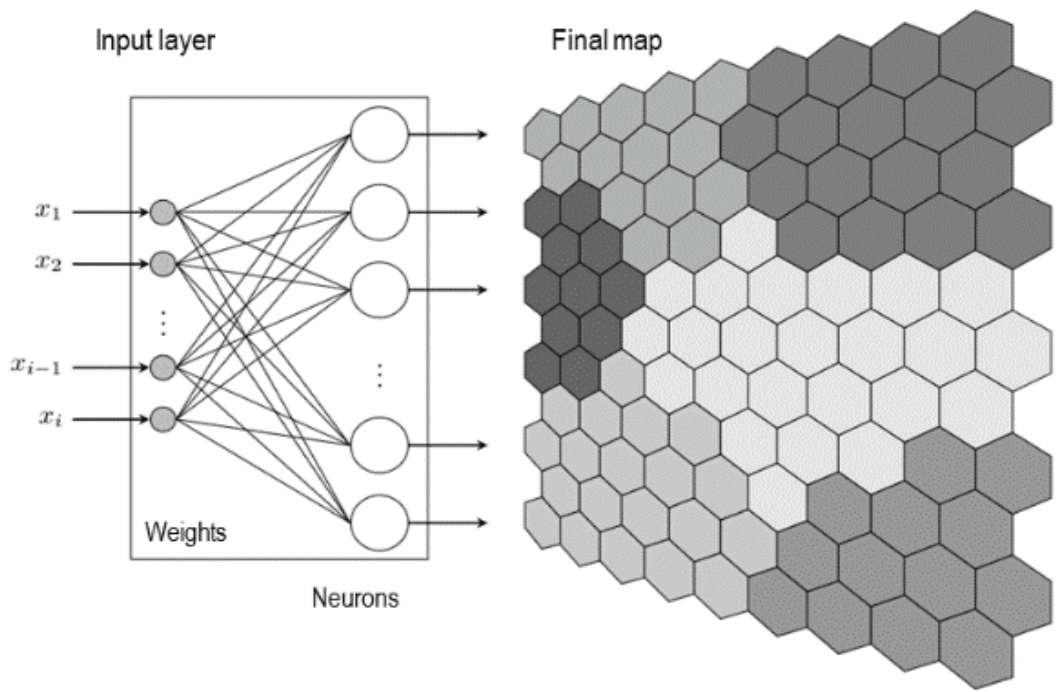

To be specific, the Kohonen map uses an unsupervised learning algorithm and places each vector in the input space on a grid. The component of the lowerdimensional grid is called a node, which is linked to a weight vector. Each weight vector is of the same dimension as the input data vector, and is projected onto a node in the grid space. The algorithm works as the following:

1. Let the input data map size be $\mathrm{R} x \mathrm{R}$, and the weight vector of node $\mathrm{i}$ is $\mu_{i}$.

2. Initialize all weight vectors, $\mu_{i}(0)$, randomly by assigning small values.

3. Randomly choose a vector $x=\left[x_{-} 1, \ldots, x_{-} n\right]$ from the input data. Compute the score, usually the Euclidian distance, $\varphi_{i}$, between $\mathrm{x}$ and node $\mathrm{i}$

$$
\varphi_{i}=\left|x-\mu_{i}(t)\right|, 1 \leq i \leq \mathrm{R}^{2}
$$

4. Find the best matching node (winning node) $\mathrm{k}$, which is the closest to the input vector, $\mathrm{x}$.

$$
\varphi_{k}=\left|x-\mu_{k}(t)\right|=\min \left\{\left|x-\mu_{i}(t)\right|\right\}, \forall i
$$


5. Adjust and update the weight vectors of the winning node, $\mathrm{k}$, and its neighborhood with a non-parametric recursive regression

$$
\mu_{i}(t+1)=\mu_{i}(t)+\rho(t)\left[x(t)-\mu_{i}(t)\right]
$$

where $\rho(t)$ is an adaptive neighborhood function that decreases as the distance between the $\mathrm{i}^{\text {th }}$ and the $\mathrm{k}^{\text {th }}$ node increases. The recursive regression ensures that the weights of any node are updated at each iteration.

6. Iterate Steps 2- 4 until the map converges and changes in the weights stabilize.

Following the initialization in Step 1, Step 2 reflects the unsupervised learning phase where the algorithm seeks associations across input values. During this stage the weight vectors span the input data space to cover its probability density. This is the topology preservation feature of the algorithm. The next step, Step 3, is the competitive phase during which the nodes compete among themselves to become the winning node, which is the node whose weight vector is the most similar to the input vector.

The cooperative phase of the algorithm is during Step 4, when the neighboring nodes update with the winning node, and that is how the resulting map as represented on a grid becomes self-organized. At the end of the training, the resulting map is called a Unified Distance Matrix (U-matrix), with additional nodes placed around the output nodes in the grid. These surrounding nodes denote the Euclidian distance between the neighboring nodes, and allow visualization of the cluster structure on the map: the lighter the color, the smaller the distance between two nodes on the grid. By placing similar input vectors closer to each other on the grid, the U-Matrix displays the clusters, uncovering the multidimensional associations within the input data space. It has to be noted that there is a trade-off in ensuring the quality of the map: well-defined clusters may not be able to preserve the topology of the input data vector, on the other hand, preserving the topology may lead to proliferation of clusters.

The idea of clustering of countries by their socio-economic development is first explored by Kaski and Kohonen (1996), Nag and Mitra (2002), Deichmann et. al. (2003) and Collan et. al. (2007). Later, Hua et al (2009) investigate the clustering patterns for 190 countries. Nguyen et al (2009) visualize province level human development in Vietnam by relying on the similarities among different human development dimensions. Pisati et al (2010) and Whelan et al (2010) apply Kohonen maps to understand multiple-deprivation profiles in Ireland using the EU 
SILC data. Recently, Vázquez and Sumner (2013) use a special case hierarchical clustering algorithm and argue that income-based categorization of countries does not adequately address the multidimensionality of economic development.

Two recent studies employ special cases of clustering and network analysis to trace the variations in the delivery of foreign aid. Coscia et. al. (2013) present an analysis of the organization and relevance of aid in recipient countries by applying a network analysis. Their results suggest that there is significant room for improvement in the coordination of aid in order to adequately address the correct combination of issues and countries. Sianesi et. al. (2014) evaluate the classification of the Commitment to Development Index of the Center for Global Development by employing a hybrid clustering methodology. In their case, the methodology relies on rating, rather than ranking, to classify the commitment of donor countries to development. Both studies argue that research into clustering of the countries may help us understand the mechanisms that can be supported for improving the efficiency of foreign aid delivery. But how do we understand the kinds of similarities in the recipient countries, considering the range of relevant factors from corruption to regime stability in the delivery of foreign aid?

\section{Description of the Data}

In this section, I provide an outline of the indicators drawn from the literature that constitute the input data for the Kohonen analysis. The dataset relies primarily on the World Bank Open Data. The working sample consists of 113 countries, which were net official development aid recipients in 2005 and in 2010, excluding the small island states. The countries included in the dataset represent $76 \%$ of the world population. In selecting the indicators I focused to the greatest extent possible on previous studies which focused on the causal relationship between foreign aid and that particular indicator. In my analysis, I will compare two Kohonen maps, one for the year 2005 and the other for the year 2010. In doing so, the maps will allow us not only to observe clustering of the selected indicators in that particular year, but also to trace the changes in clustering across the years.

In the literature, the discussion of the causal relationship between foreign aid and the institutional structure of the recipient countries has revolved around the size of the recipient country, its level of need and ability to administer aid funds (Cogneau and Naudet, 2007; Wood, 2008). The first indicator included into the input data vector is the net official development aid per capita. The next indicator in the input space is the size of military. By changing budgetary priorities, foreign aid 
may be associated with an increase in military expenditures (Gomanee et. al., 2005; Savun and Tirone, 2011). It is reasonable to assume that the complex ways in which aid intersects with different sectors of an economy would not leave the size of the military sector unaffected. The third indicator is the average precipitation during the previous year in the country. In a world where climate change affects mostly poor and aid-dependent countries, the availability of water for human use and agriculture production is undoubtedly as important as access to safe water (Alabi, 2014). The next indicator selected for the input space is the prevalence of non-communicable diseases (NCDs), such as cardio-vascular diseases, diabetes, or cancer. While the literature on foreign aid has mostly been concerned with communicable diseases, such as HIV/AIDS and tuberculosis for public health reasons, the evidence suggests that death rates due to NCDs are higher than those recorded for communicable diseases (Nugent and Feihl, 2011; Bikbov et. al., 2014). Furthermore, for my purposes in seeking the similarities between the institutional structures among aidrecipient countries, the prevalence of NCDs is a proxy for continuous strain on the country health system, in addition to representing the access to and affordability of health sęrvices in the country.

The remaining indicators concern governance and population structure in the recipient countries. As a measure of governance, I selected an indicator for informal payments to public officials. The relationship between aid and corruption has been investigated and the general finding seems to be that aid is less effective in more corrupt countries (Okada and Samreth, 2012; Tezanos et. al., 2013; Acht et.al., 2015). The other indicator for governance measures the aid absorption capacity and bureaucratic design of the recipient country (Feeny and de Silva, 2012; Arel-Bundock, et.al., 2015). The institutional ability of a recipient government to administer aid funds is expected to be a factor in whether funding will be approved by the donors. The indicator measuring the absorption capacity of an aid-recipient country is drawn from the database of Worldwide Governance Indicators (Kaufmann et. al., 2011). The next indicator representing governance institutional structure comes from the POLITY IV dataset and measures regime stability. This indicator is a proxy for the stability of governing institutions (Chauver, 2002; Marshall and Jaggers, 2011).

Finally, as an indicator of population structure, I use ethno-lingual fraction as an indicator in the input space. The ways in which sub-populations can communicate and interact with one another is expected to influence how the society coordinates and cooperates in the distribution of public resources. The source of this indicator is the dataset provided by Desmet et. al. (2012). And, lastly, the functionality of access to markets is measured by an indicator of the road density per $100 \mathrm{~km}$ square, 
available from the World Bank Open Data.

The indicator selection process following the review of the literature and available data sets brings the total number of indicators to 9 . These indicators and the summary measures are listed in Table 1.

Table 1

Foreign Aid and Institutional Context: Summary Statistics

\begin{tabular}{|c|c|c|c|c|c|c|}
\hline Indicator & Description (Reference Study) & Min & Max & Avg. & $\begin{array}{c}\text { Std } \\
\text { Dev }\end{array}$ & Data Source \\
\hline \multicolumn{7}{|c|}{2005} \\
\hline NetODA & Net ODA received per capita (current US\$) & 1.01 & 805.68 & 55.76 & 91.05 & (1) DT.ODA.ODAT.PC.ZS \\
\hline MilitaryGDP & $\begin{array}{l}\text { Military expenditure (\% of GDP) (Reference: Gomanee } \\
\text { et al 2005, Savun and Tirone 2011) }\end{array}$ & 0.10 & 20.87 & 2.16 & 2.15 & (1) MS.MIL.XPND.GD.ZS \\
\hline Rain & $\begin{array}{l}\text { Average precipitation in depth ( } \mathrm{mm} \text { per year) (Reference: } \\
\text { Alabi 2014) }\end{array}$ & 51.00 & 3142.00 & 1169.01 & 791.66 & (1) AG.LND.PRCP.MM \\
\hline NCD & $\begin{array}{l}\text { Cause of death, by non-communicable diseases (\% of } \\
\text { total) (Reference: Nugent and Feihl 2011, Bikbov et al } \\
\text { 2014) }\end{array}$ & 17.85 & 93.75 & 51.85 & 23.94 & (1) SH.DTH.NCOM.ZS \\
\hline Corruption & $\begin{array}{l}\text { Informal payments to public officials (\% of firms) } \\
\text { (Reference: Okada and Samreth 2012, Tezanos et al } \\
\text { 2013) }\end{array}$ & 3.00 & 98.26 & 37.92 & 22.91 & (1) IC.FRM.CORR.ZS \\
\hline GovEffectiveness & $\begin{array}{l}\text { Government Effectiveness (Reference: Feeny and de } \\
\text { Silva 2012, Chauver 2002) }\end{array}$ & -2.17 & 1.22 & -0.64 & 0.60 & (2) \\
\hline RoadDensity & $\begin{array}{l}\text { Road density (km of road per } 100 \mathrm{sq} . \mathrm{km} \text { of land area) } \\
\text { (Reference: Kaufmann et al 2011) }\end{array}$ & 0.50 & 191.05 & 25.04 & 31.97 & (1) IS.ROD.DNST.K2 \\
\hline EthnoLngFract & Ethno-lingual Fraction (Reference: Desmet et al (2012) & 0.00 & 0.90 & 0.36 & 0.27 & (3) \\
\hline RegimeStability & $\begin{array}{l}\text { Regime Durability (Reference: , Marshall and Jaggers } \\
\text { 2011) }\end{array}$ & 0.00 & 86.00 & 14.36 & 15.99 & (4) \\
\hline \multicolumn{7}{|c|}{2010} \\
\hline NetODA & Net ODA received per capita (current US\$) & 0.07 & 660.88 & 72.02 & 87.12 & (1) DT.ODA.ODAT.PC.ZS \\
\hline MilitaryGDP & $\begin{array}{l}\text { Military expenditure (\% of GDP) (Reference: Gomanee } \\
\text { et al 2005, Savun and Tirone 2011) }\end{array}$ & 0.10 & 25.00 & 2.28 & 2.58 & (1) MS.MIL.XPND.GD.ZS \\
\hline Rain & $\begin{array}{l}\text { Average precipitation in depth ( } \mathrm{mm} \text { per year) (Reference: } \\
\text { Alabi 2014) }\end{array}$ & 51.00 & 3142.00 & 1169.01 & 791.66 & (1) AG.LND.PRCP.MM \\
\hline $\mathrm{NCD}$ & $\begin{array}{l}\text { Cause of death, by non-communicable diseases (\% of } \\
\text { total) (Reference: Nugent and Feihl 2011, Bikbov et al } \\
\text { 2014) }\end{array}$ & 19.00 & 95.20 & 55.47 & 23.28 & (1) SH.DTH.NCOM.ZS \\
\hline Corruption & $\begin{array}{l}\text { Informal payments to public officials (\% of firms) } \\
\text { (Reference: Okada and Samreth 2012, Tezanos et al } \\
\text { 2013) }\end{array}$ & 0.70 & 85.00 & 30.95 & 21.35 & (1) IC.FRM.CORR.ZS \\
\hline GovEffectiveness & $\begin{array}{l}\text { Government Effectiveness (Reference: Feeny and de } \\
\text { Silva 2012, Chauver 2002) }\end{array}$ & -2.24 & 1.26 & -0.60 & 0.63 & (2) \\
\hline RoadDensity & $\begin{array}{l}\text { Road density (km of road per } 100 \mathrm{sq} . \mathrm{km} \text { of land area) } \\
\text { (Reference: Kaufmann et al 2011) }\end{array}$ & 0.50 & 201.28 & 26.74 & 34.32 & (1) IS.ROD.DNST.K2 \\
\hline EthnoLngFract & Ethno-lingual Fraction (Reference: Desmet et al (2012) & 0.00 & 0.90 & 0.36 & 0.27 & (3) \\
\hline RegimeStability & $\begin{array}{l}\text { Regime Durability (Reference: , Marshall and Jaggers } \\
\text { 2011) }\end{array}$ & 0.00 & 91.00 & 17.27 & 16.93 & (4) \\
\hline
\end{tabular}

(1) World Bank Open Data

(2) World Governance Indicators Daniel Kaufmann, Aart Kraay and Massimo Mastruzzi (2011). The Worldwide Governance Indicators: Methodology and Analytical Issues. Hague Journal on the Rule of Law, 3, pp 220-246. doi:10.1017/S1876404511200046.

(3) The political economy of linguistic cleavages, Klaus Desmet, Ignacio Ortuño-Ortín, Romain Wacziarg Journal of Development Economics 97 (2012) $322-338$

(4) POLITY IV Marshall, M. G., \& Jaggers, K. (2011). Polity IV project: Political regime characteristics and transitions. Center for GlobalPolicy, School of Public Policy, George Manson University. Retrieved July 24, 2014 from http://www.systemicpeace.org/ 


\section{DISCUSSION}

The Kohonen maps display the associations among the high dimensional data, which would not otherwise be clearly visible. In this case using 9 indicators and 113 countries, I selected a 9 by 12 map with 108 estimated vectors, each of which has 9 estimated components, equivalent to the number of indicators. Each of the 113 countries is positioned on the map on the basis of the smallest Euclidian distance between its input data vector and each of the 108 estimated vectors.

Before running the algorithm, all variables must be standardized to prevent scale-based distortions in calculating the Euclidian distances. The preliminary analysis begins with constructing the D-matrix to display the clusters of countries following the training of the input vector data.

The cluster structure driven by the Kohonen map algorithm is displayed by two main maps, the U-matrix and the component planes. After the training, each country is placed on a node in the U-matrix. As mentioned above, the placement of a country is set by the minimum Euclidian distance between its input data vector and the estimated weight vectors. Therefore, the high dimensional association between the countries is reduced to a two-dimensional grid, represented by the U-matrix. It is possible that a node may contain several countries if the input data vector of each country is similar to the input data vectors of the other countries on the same node.

Additionally, the number of nodes in the U-matrix exceeds the number of nodes in the D-matrix; these additional nodes denote the distance between the weight vectors of the two neighboring nodes. The distance between the two neighboring nodes is shaded from light to dark, that is, the darker the node, the greater the distance. Figures $2 \mathrm{~A}$ and $2 \mathrm{~B}$, and Figures $3 \mathrm{~A}$ and $3 \mathrm{~B}$ depict the clustering with and without these additional nodes that denote distance between the clusters. For instance, a white node signals that the distance between the two neighboring nodes is small, whereas a black node signals that the neighboring nodes are distant from each other, set by the values of the estimated weight vectors. (Deichmann et. al., 2007; Hua et. al., 2009). 
Figure 2A

2005 U-matrix: A dark empty node indicates high distance between the two occupied nodes nearby. For comparison, Figure 2B depicts the cluster of countries without the distance nodes.

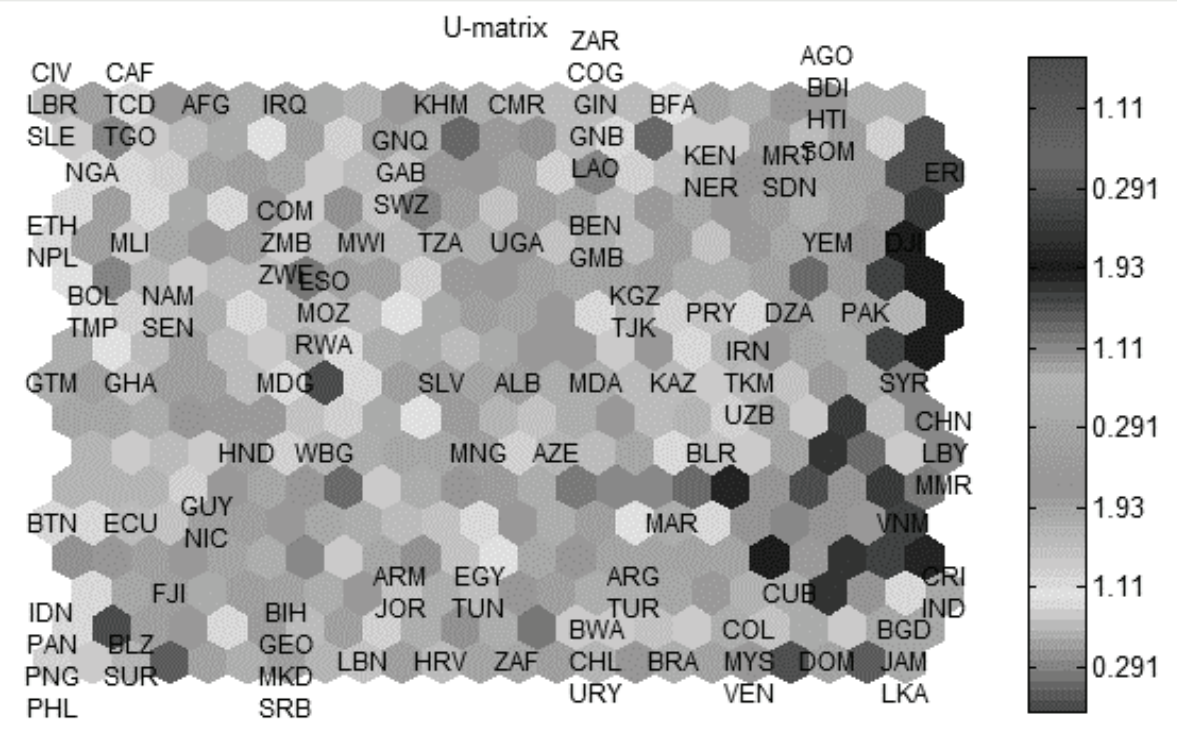

Figure 2B

The placement of countries on the U-matrix without the distance nodes

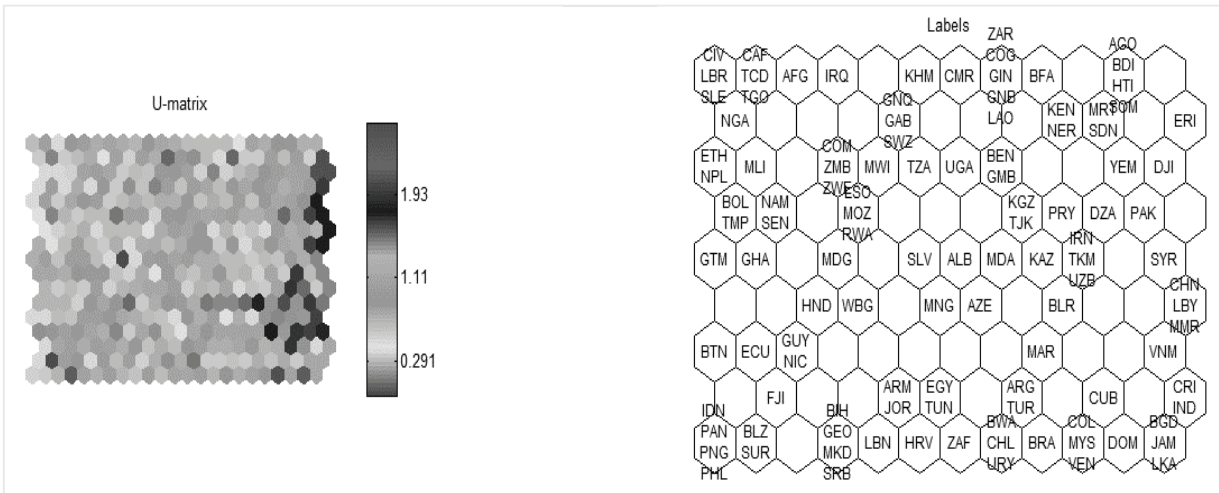




\section{Figure 3A}

2010 U-matrix: A dark empty node indicates high distance between the two occupied nodes nearby. For comparison, Figure 3B depicts the cluster of countries without the distance nodes.

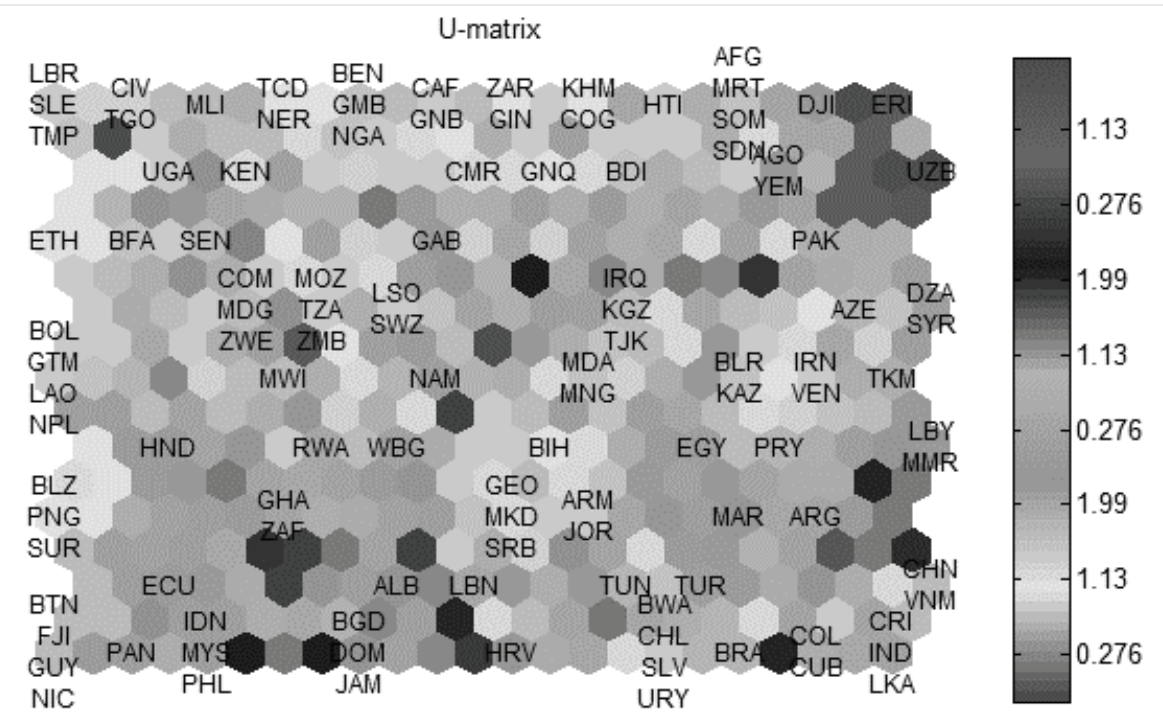

Figure 3B

The placement of countries on the U-matrix without the distance nodes.
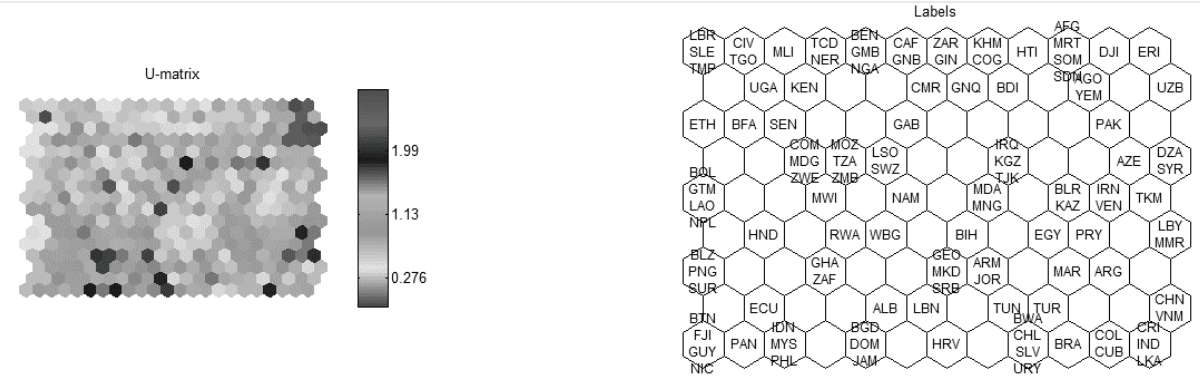

Identification of the clusters, which is the driving mechanism of Kohonen map, should be sufficiently stable only if the variations between the identified clusters exceed the variations within the clusters. Davies and Boulding (1979) propose an index which aims to minimize the ratio of the within-cluster variation to the between-cluster variation. The panels displayed in Figure 4 present the Davies - Boulding index and the suggested k-means clustering. The index value shows 
that the number of clusters declined from 11 in the year 2005 to 9 in the year 2010, suggesting that the countries included in the sample have converged to a smaller number of clusters over time by the indicators chosen for this analysis.

Figure 4

David-Boulding Index and k-Means Clustering

\begin{tabular}{ll}
2005 \\
\hline
\end{tabular}

Table 2 presents the means of the indicators by clusters for 2005 and 2010 as delineated by the Davies - Boulding index. The Table provides preliminary evidence that foreign aid can be allocated more efficiently, depending on the program targets. For instance, in 2005, the countries in Group 3 received higher foreign aid (\$66 per capita) than the countries in Group 8 (\$54 per capita), although the countries in Group 8, on average, suffered from higher deaths from NCDs, have relatively less corruption and are characterized by more stable regimes. Similarly, the countries in Group 5 received less foreign aid (\$16 per capita) than the countries in Group 11 (\$36 per capita), even though the countries in Group 11 have lower deaths by NCD and exhibit relatively higher corruption and less stable regimes. In 2010, we observe that 11 countries in Group 5 received the lowest level of foreign aid per capita. Yet, these countries exhibit high stress on the health sector, as represented by the deaths from NCDs, compared with the countries in other clusters. 


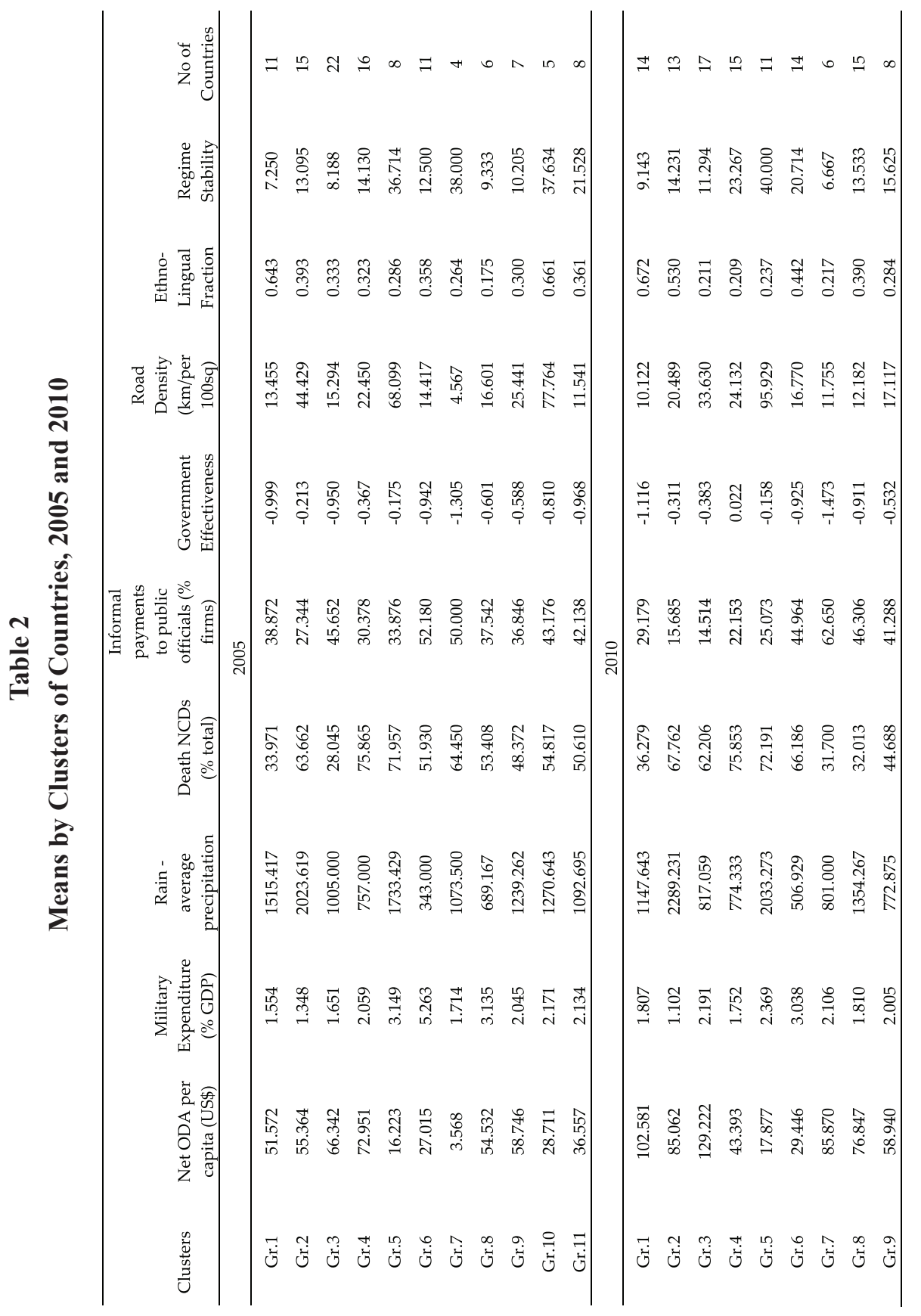


The component maps, Figures 5A and 5B, display a clear visualization of the estimated weight vector for each indicator in the input space placed on the grid. As such, it is possible to identify the direction of each input vector by tracing from light to dark nodes as the component value increases. For example, in 2010, the component map of the input corresponding to regime stability shows that the duration of regime shortens from the upper left corner to the lower right corner. Just as the U-matrix map displays the clustering by the associations at the high dimension input data, the interpretation of moving across the U-matrix is provided by the directions in the component maps.

For instance, the directions of the components maps in 2005 and in 2010 indicates that net official per capita aid was highest in countries with corruption measured at medium levels. In 2005, net official per capita aid is recorded high in countries with relatively low regime stability. In contrast, in 2010, the pattern of net official per capita aid seems to have shifted, it was higher in countries with high ethno-language fractions. 


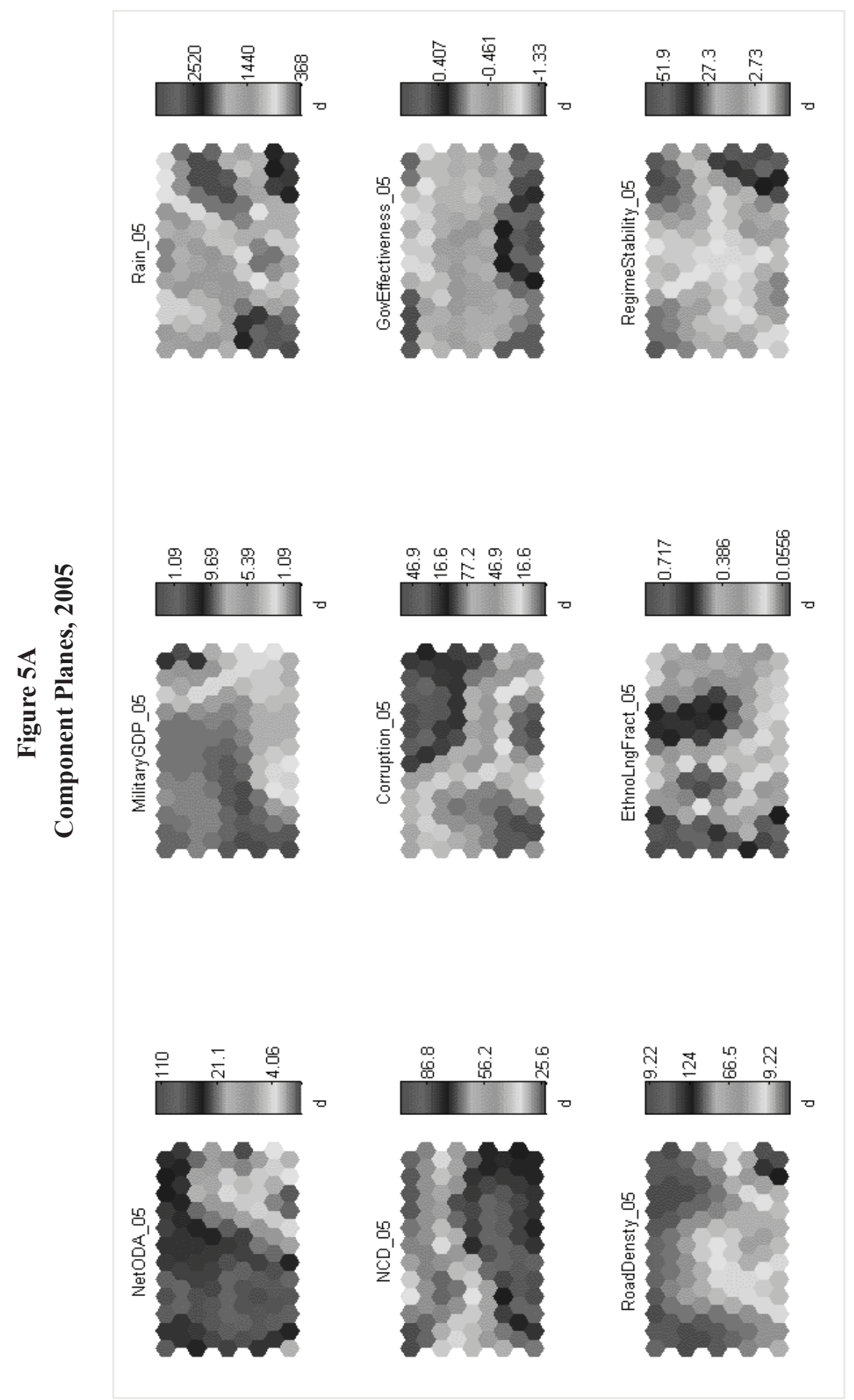




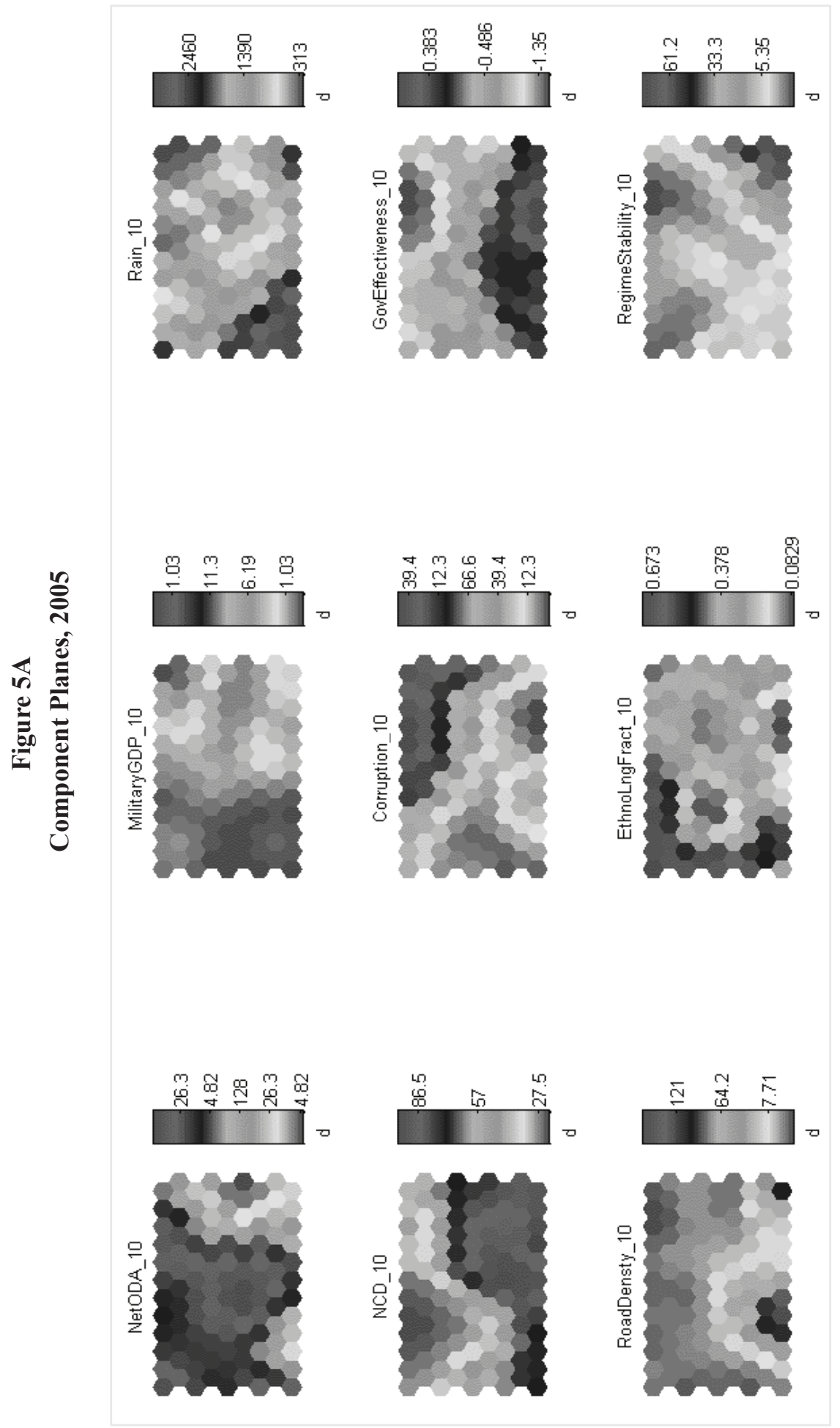




\section{CASE STUDIES}

It is essential to understand why some countries show progress as recipients of aid while others lag behind. The Kohonen maps provide a novel way of considering how foreign aid operates in relation to the institutional factors that were highlighted in the literature. Before proceeding, it is essential to emphasize that neither the unit of analysis - the countries -, nor the indicators included in this analysis need to be the final selections. My analysis relies on an extensive reading of the literature and publicly available datasets to illuminate the contribution of Kohonen maps to ask new questions about efficient and effective methods of delivering foreign aid.

The Kohonen maps displayed in Figures 2A and 2B place Nigeria close to Ethiopia and Nepal for the year 2005. By 2010, in Figures 3A and 3B Nigeria moves to occupying the same node with Benin and Gambia. The component planes, displayed in Figures 5A and 5B, corresponding to corruption indicate that the level of corruption in Nigeria has increased during that time, but the level of official development aid the country has received stayed at the same level in comparison to other countries. Similarly, in 2005 and in 2010, we observe that Pakistan was placed close to Yemen. In none of these countries, the level of per capita official development aid has changed, but the prevalence of deaths due to NCDs have increased in Pakistan between 2005 and 2010, suggesting a need to reconsider the allocation of health-related foreign aid in the country. Iraq, which in 2005 shared the same node with Afghanistan, moved to the same node with Kyrgyzstan and Tajikistan in 2010. Iraq remained one of the most highly aid-dependent countries, as the component plane shows, but deaths due to NCDs increased by 2010, as we observe in Pakistan.

Egypt in 2005 was placed near Tunisia by the similarity in their structural parameters. Yet, in 2010, Egypt was more similar to Paraguay, whereas Tunisian indicators were closer to those of Turkey. From 2005 to 2010, the component planes associated with government effectiveness shows that in Egypt, the effectiveness of government declined, even though the net official per capita development aid remained high. What does this tell us? For one thing, the institutional structure in Egypt represented by the indicators may not be as close to that of the countries in the same region. Furthermore, plans to direct official development aid to Tunisia could consider that the institutional structure in Tunisia resembled Turkey in 2010.

In 2005, the Kohonen map algorithm placed China, Libya and Myanmar on the same node. In 2010, China leaves its previous cluster and is placed on the same node with Vietnam. During this period, the per capita net official development aid 
in China dropped, so did the level of corruption. Libya and Myanmar are placed on the same node in both years.

An interesting example is Bangladesh, which shared similar characteristics, as reflected by the indicators included, with Sri Lanka and Jamaica in 2005. In 2010, the institutional structure in Bangladesh shows more similarity with Dominica and Jamaica. One implication of these bilateral comparisons of Bangladesh with the other countries is that geographical neighborhood, while highly correlated with the institutions of a country, may not carry the greatest weight in considering aid allocations.

\section{CONCLUSION}

The study of foreign aid has tended to focus almost exclusively on finding the causal relationship between development aid and economic growth. However, aid operates in a complex environment in which drawing causal relationships is extremely difficult. And evaluating the impact of aid which varies in form depending on the country context in which it takes place is a complex task.

This paper argues that one way to improve aid effectiveness would be to draw on the structural and climate-based similarities between the aid-recipient countries. Once the similarities between the countries are established, it becomes possible to investigate further the kind of aid that these countries have received. Looking at bilateral institutional similarities may encourage mutual learning among the aidrecipient countries, in addition to signaling to the donors of the characteristics of the recipients' institutional structure which may not be immediately observable.

The contribution of this study is to suggest that Kohonen maps, which enable visualization of associations within a set of multidimensional factors, can be employed to design multi-pronged aid delivery policies. In the particular context that I employed Kohonen maps, the findings suggest that aid allocation and coordination could be based on institutional similarities rather than the geographical proximity of recipient countries or the cultural ties (preferences) between the donor and recipient countries.

Measuring aid effectiveness and deciding on aid allocation has become more challenging and has made multi-dimensional taxonomies increasingly important. The analysis offered here also partially answers the questions that were raised recently regarding the delivery and future of aid, when the majority of the poor live in non-poor, medium income countries (Sumner and Mallett, 2013). For this reason, drawing on similar institutional structures can be expected to increase the targeting 
effectiveness of aid allocation and coordination. To be sure, Kohonen maps are neither as simple or widely accepted as other simpler taxonomies, such as HDI, but it is a tool flexible enough for the donors and country partners to employ in deciding on how to distribute aid according to their priority concerns.

Obviously, this study raises more questions than it answers. Further studies expanding the number of indicators or extending the time period covered would be welcome. Among the possibilities are questions such as: To what extent does the clustering pattern change with the MDG outcomes? What kind of aid modalities might have worked in Tunisia in 2005 but not in 2010? In what ways do the Kohonen maps support opportunities for learning in the field, especially considering donor proliferation in the aid-dependent countries? The challenge for future work will be to expand the questions set, a challenge that may be best addressed by a methodology that benefits from the use of Kohonen maps.

\section{REFERENCES}

Acht, M., Mahmoud, T.O., \& Thiele, R. (2015). Corrupt governments do not receive more state-to-state aid: Governance and the delivery of foreign aid through nonstate actors. Journal of Development Economics, 114, 20-33

Alabi, R. A. (2014). Impact of agricultural foreign aid on agricultural growth in SubSaharan Africa. Agrodep Working Paper 006.

Arel-Bundock, V., Atkinson, J., \& Potter, R.A. (2015). The limits of foreign aid diplomacy: How bureaucratic design shapes aid distribution. International Studies Quarterly, 59, 544 - 556

Arndt, C., Jones, S., \& Tarp, F. (2015). Assessing foreign aid's long run contribution to growth and development. World Development, 69, 6 - 18. http://doi. org/10.1016/j.worlddev.2013.12.016

Arndt, C. Jones, S. \& Tarp, F. (2010). Aid, growth, and development: Have we come full circle? Journal of Globalization and Development, 1(2), 1-30, doi: $10.2202 / 1948-1837.1121$

Ball, R. (2010). Cultural values and public policy: The case of international development aid. Quarterly Review of Economics and Finance, 50, 3-16

Bikbov, B., Perico, N. \& Remuzzi, G. (2014). Mortality landscape in the global burden of diseases, injuries and risk factors study. European Journal of Internal Medicine, 25, 1-5.

Burnside, C. and Dollar, D. (2000). Aid, policies, and growth. American Economic Review, 90 (4), 847-868. 
Busse, M., and Gröning, S. (2009). Does foreign aid improve governance? Economics Letters 104: 76-78

Chauvet, L. (2002). Socio-political instability and the allocation of international aid by donors. European Journal of Political Economy 19: 33-59

Collan, M., Eklund, T., \& Back, B. (2007). Using the self-organizing map to visualize and explore socio-economic development. EBS Review 22 (1), 6-15.

Cogneau, D., and Naudet. J. D. (2007). Who deserves aid? Equality of opportunity, international aid, and poverty reduction. World Development 35 (1), 104-120.

Coscia, M., Hausmann, R., \& Hidalgo, C.A. (2013). The structure and dynamics of international development assistance. Journal of Globalization and Development, 3(2), 1- 42.

d'Aiglepierre, R. and Wagner, L. (2013). Aid and universal primary education. Economics of Education Review, 37: 95-112

De Matteis, A. (2013). Relevance of poverty and governance for aid allocation. Review of Development Finance, 3: 51-60.

Dalgaard, C. J. (2008). Donor policy rules and aid effectiveness. Journal of Economic Dynamics \& Control 32: 1895-1920.

Davies, D. L. and Bouldin, D. W. (1979). A cluster separation measure. IEEE Transactions on Pattern Analysis and Machine Intelligence, Pami-1, no.2: 224 $-227$

Deichmann, J. I., Eshgi, A., Haughton, D., Sayek, S, Teebagy, N., \& Topi, H. (2003). Geography matters: Kohonen classification of determinants of foreign direct investment in transition countries. Journal of Business Strategies, 20(1), 23 44.

Deichmann, J. I., Eshgi, A., Haughton, D., Woolford, D. \& Sayek, S. (2007). Measuring the international digital divide: an application of Kohonen selforganising maps. International Journal Knowledge and Learning, 3 (6), 552 -575 .

Desmet, K., Ortuño-Ortín, I. \& Wacziarg, R. (2012). The political economy of linguistic cleavages. Journal of Development Economics, 97: 322-338.

Djankov, S., Montalvo, J. G., \& Reynal-Querol, M. (2009). Aid with multiple personalities. Journal of Comparative Economics 37: 217-229

Doucouliagos, H., and Paldam, M. (2008). Aid effectiveness on growth: A meta study. European Journal of Political Economy, 24, 1-24.

Doucouliagos, H., and Paldam, M. (2011). The ineffectiveness of development aid on growth: An update. European Journal of Political Economy, 27, 399-404. 
Easterly, W. (2003). Can Foreign Aid Buy Growth? Journal of Economic Perspectives, 17 (3), 23-48.

Feeny, S., and de Silva, A. (2012). Measuring absorptive capacity constraints to foreign aid. Economic Modelling, 29: 725-733.

Fuchs, A., Nunnenkamp, P., \& Öhler, H. (2015). Why donors of foreign aid do not coordinate: The Role of competition for export markets and political support. The World Economy, 255 - 285.

Gomanee, K., Morissey, O., Mosley, P. \& Verschoor. A. (2005). Aid, government expenditure, and aggregate welfare. World Development, 33 (3), 355-370.

Gulrajani, N. (2011). Transcending the great foreign aid debate: managerialism, radicalism and the search for aid effectiveness. Third World Quarterly, 32 (2), 199-216, DOI:10.1080/01436597.2011.560465

Hansen, H., and Tarp, F. (2001). Aid and growth regressions. Journal of Development Economics, 64: 547-570

Hua, G., Skaletsky, M. \& Westermann, K. (2009). Exploratory analysis of CIA factbook data using Kohonen self-organizing maps. Case Studies in Business, Industry and Government Statistics, 3 (1), 48-59.

Hudson, J. (2013). Promises kept, promises broken? The relationship between aid commitments and disbursements. Review of Development Finance, 3, 109-120

Jagric, T., Bojnec, S. \& Jagric, V. (2015). Optimized spiral spherical self-organizing map approach to sector analysis - The case of banking. Expert Systems with Applications, 42(13), 5531 - 5540.

Kaski, S., and Kohonen, T. (1996). Exploratory data analysis by the self-organizing map: Structures of welfare and poverty in the world. In Neural networks in financial engineering. Proceedings of the third international conference on neural networks in the capital markets, London. World Scientific Pub (pp. 498507).

Kaufmann, D., Kraay, A., \& Mastruzzi, M. (2011). The worldwide governance indicators (WGI) project. Retrieved July 24 2014, from http://info.worldbank. org/governance/wgi/index.aspx\#home

Kersting, E., and Kilby, C. (2014). Aid and democracy redux. European Economic Review, 67,125-143.

Kimura, H., Mori, Y., \& Sawada, Y. (2012). Aid proliferation and economic growth: A cross-country analysis. World Development 1(40), 1-10.

Kjeizer, N. (2012). The future of development cooperation: From aid to policy coherence for development? Working Paper. Brussels: ECDPM. 
Kohonen, T. (2013). Essentials of the self-organizing map. Neural Networks, 37, $52-65$.

Kosack, S. (2003). Effective Aid: How Democracy Allows Development Aid to Improve the Quality of Life. World Development, 31(1), 1-22.

Kourtellos, A., Tan, C.M., \& Zhang, X. (2007). Is the relationship between aid and economic growth nonlinear? Journal of Macroeconomics 29: 515-540

Lof, M., Mekasha, T.J., \& Tarp, F. (2015). Aid and income: Another time-series perspective. World Development, 69, 19 - 30. http://dx.doi.org/10.1016/j. worlddev.2013.12.015

McGillivray, M. (2004). Descriptive and prescriptive analyses of aid allocation: Approaches, issues, and consequences. International Review of Economics and Finance, 13: 275-292.

Marshall, M. G., Gurr, T.R., \& Jaggers, K. (2011). Polity IV project: Political regime characteristics and transitions. Center for GlobalPolicy, School of Public Policy, George Manson University. Retrieved July 24, 2014 from http://www. systemicpeace.org/

Minoiu, C. and Reddy. S.G. (2010). Development aid and economic growth: A positive long-run relation. Quarterly Review of Economics and Finance, 50, 27-39

Mishra, P. and Newhouse, D. (2009). Does health aid matter? Journal of Health Economics, 28, 855-872

Nguyen, P., Haughton, D., \& Hudson, I. (2009). Living standards of Vietnamese provinces: A Kohonen map. Case Studies in Business, Industry and Government Statistics 2 (2), 109-113

Nugent, R. A., and Feigl, A.B. (2010). Where have all the donors gone? Scarce donor funding for non-communicable diseases. Center for Global Development Working Paper No. 228

Okada, K., and Samreth, S. (2012). The effect of foreign aid on corruption: A quantile regression approach. Economics Letters, 115, 240-243.

Pisati, M., Whelan, C., Lucchini, M., \& Maître. B. (2010). Mapping patterns of multiple deprivation using self-organising maps: An application to EU-SILC data for Ireland. Social Science Research, 39 (3), 405-418. doi:10.1016/j. ssresearch.2009.11.004

Savun, B., and Tirone, D.C. (2011). Foreign aid, democratization, and civil conflict: How does democracy aid affect civil conflict? American Journal of Political Science, 55 (2), 233-246 
Sianes, A., Dorado-Moreno, M., \& Herva's-Martinez, C. (2014). Rating the rich: An ordinal classification to determine which rich countries are helping poorer ones the most. Social Indicators Research 116: 47-65 doi: 10.1007/s11205-0130270-6

Sumner, A., and Vázquez, S. T. (2014). How has the developing world changed since the late 1990s? A dynamic and multidimensional taxonomy of developing countries. Center for Global Development Working Paper No. 375

Sumner, A., and Mallett. R. (2013). The Future of Foreign Aid: Development Cooperation and the New Geography of Global Poverty Palgrave Macmillan: New York.

Tezanos, S., Quiñones, A., \& Guijarro. M. (2013). Inequality, aid and growth: macroeconomic impact of aid grants and loans in Latin America and the Caribbean. Journal of Applied Economics, 16 (1), 153-177

Torsvik, G. (2005). Foreign economic aid; should donors cooperate? Journal of Development Economics, 77: 503-515

Vázquez, S. T., and Sumner, A. (2013). Revisiting the meaning of development: A multidimensional taxonomy of developing countries. Journal of Development Studies, 49 (12), 1728-1745. doi: 10.1080/00220388.2013.822071

Whelan, C.T., Lucchini, M., Pisati, M. \& Maître, B. (2010). Understanding the socioeconomic distribution of multiple deprivation: An application of self-organising maps. Research in Social Stratification and Mobility, 28 (3), 325 - 342.

Winters, M.S., and Martinez, G. (2015). The role of governance in determining foreign aid flow composition. World Development, 66, 516 - 531.

Wood, A. (2008). Looking ahead optimally in allocating aid. World Development, 36(7), 1135-1151.

\section{BRIEF BIOGRAPHICAL SKETCH OF AUTHOR}

Dr. Sevinc Rende is an Assistant Professor of Economics at Isik University, Istanbul Turkey. She specializes in analysis of social and economic policy interactions in transition and post-conflict societies, with subfields in aid modality and incomplete welfare systems. 